\title{
A Comparative Study of Sexual Dysfunction in Schizophrenia Patients Taking Aripiprazole Versus Risperidone
}

\section{Shah SK}

Corresponding author

Sunil Kumar Shah

Department of Psychiatry

College of Medical Sciences

Bharatpur

Email: sunilshah141@hotmail.com

\section{Citation}

Shah SK. A Comparative Study of Sexual Dysfunction in Schizophrenia Patients Taking Aripiprazole Versus Risperidone. Kathmandu Univ Med J 2013;42(2):121125.

\section{ABSTRACT \\ Background}

Sexual dysfunction due to antipsychotics is a significant problem encountered with first-generation antipsychotics. Even the second-generation antipsychotics like risperidone are not free of sexual dysfunction due to its D2 blocking properties leading to hyperprolactinaemia. Newer antipsychotic aripiprazole, partial dopamine agonist, with neutral effect on prolactin level or even decreasing it, is associated with avoidance of sexual dysfunction.

\section{Objectives}

To assess the effect of risperidone and aripiprazole on sexual function of schizophrenic patients.

\section{Methods}

This was an open-label, cross-sectional, observational study conducted at College of Medical Sciences, Bharatpur. Schizophrenic patients attending OPD and inpatient, taking risperidone or aripiprazole for at least two months were included in this study. Forty one patients, without chronic medical illness and sexual dysfunction before starting drugs, with informed consent were studied during Jan 2012 and Aug 2012.

\section{Results}

Changes in sexual activity was found in $11(55 \%)$ of those taking risperidone while, only $3(14.3 \%)$ had any kind of sexual difficulty. This was statistically significant $(p=0.006)$. Majority, $92.7 \%$ of the patients did not report about changes in sexual activity spontaneously.

\section{Conclusion}

Sexual dysfunction was statistically significantly higher in those taking risperidone. Prevalence of sexual dysfunction was low with aripiprazole. Except those having poor sexual functions due to the drugs, the majority had to be specifically inquired about the effects of drug on sex life.

\section{KEY WORDS}

Aripiprazole, risperidone, schizophrenia, sexual dysfunction

\section{INTRODUCTION}

Sexual relationships are central to the lives of most of us. Sexual dysfunction is uninvestigated significant public health problem. In the brain, sexual excitation depends to a considerable extent on dopamine and noradrenaline, and serotonin has a central role in the inhibitory system. ${ }^{1}$ In many countries of the industrialised world secondgeneration ("atypical") antipsychotics (SGAs) have become the first line drug treatment for people with schizophrenia. ${ }^{2}$ The question as to whether and if so how much the effects of the various SGAs differ is a matter of debate. Disturbances in sexual function can occur with a number of antipsychotics including first and second generation agents. ${ }^{3}$ DSM-IV-TR (Diagnostic and Statistical Manual of Mental DisordersFourth Edition-Text Review) defines sexual dysfunction as characterized by disturbance in sexual desire and in the psychophysiological changes that characterize the sexual response cycle and cause marked distress and interpersonal 
difficulty. ${ }^{4}$ Aripiprazole is a partial agonist at D2 and a potent antagonist at 5-HT2A. Aripiprazole is effective in the treatment of acute psychosis in schizophrenia similar to that of risperidone. It is administered at dosage between 10 and $30 \mathrm{mg}$ daily. It is associated with less rate of extrapyramidal side effects, is the least sedating, not associated with QT prolongation and minimal weight gain and sexual dysfunction. ${ }^{5}$ While risperidone causes prolactin related disruption of hypothalamic-pituitary-gonadal axis that leads to decreased sexual interest and impaired sexual function. ${ }^{6}$ This study was carried out to evaluate sexual dysfunction in schizophrenic patients taking aripiprazole and risperidone.

\section{METHODS}

Patients presenting in Psychiatry OPD and inpatient ward at College of Medical Sciences, Bharatpur, receiving aripiprazole or risperidone for schizophrenia for at least for two months continuously were included in the study with informed consent, between Jan 2012 to Aug 2012. Those who had sexual dysfunction prior to starting antipsychotics or with chronic medical illnesses were excluded. Psychotropic related sexual dysfunction Questionnaire was used to assess them. SPSS 20 was used to analyze the data. Purposive sampling technique was used and a total of 41 patients fulfilling the inclusion criteria and accepting to be included in the study with informed consent were studied.

\section{RESULTS}

A total of 41 patients, receiving risperidone or aripiprazole for schizophrenia for at least two months continuously were included in this study.

Table 1 shows that there were 20 patients taking risperidone and 21 taking aripiprazole. There was no statistical significant difference in the age groups taking either drug $(p=0.731)$.

Table 1. Age group.

\begin{tabular}{|lccc|}
\hline \multicolumn{1}{|c}{ Age groups } & \multicolumn{2}{c}{ Drug used } & Total \\
& Risperidone & Aripiprazole & \\
\hline $25-39$ & 17 & 17 & 34 \\
\hline 40 and above & 3 & 4 & 7 \\
\hline Total & 20 & 21 & 41 \\
\hline
\end{tabular}

Table 2 shows sex distribution with drugs. There were 16 males and four females with risperidone while 17 males and four females with aripiprazole with no statistical difference in the two groups (0.939).

Table 3 shows that majority of the patients were Hindus in both the drug groups, 17 in risperidone and 18 in aripiprazole with no statistical significant difference in the two drug groups $(p=0.309)$.

Table 4 shows that, the distribution of the patients in various socioeconomic groups was similar in both the study drug groups $(p=0.785)$. Majority of patients were in the lower middle class with 15 in risperidone and 16 in aripiprazole group.

Table 5 shows the educational status of the patients, without any statistical significant difference $(0.651)$ in the two groups. Majority of the patients included in the study were educated up to intermediate level or below, only three patients were graduate or post-graduates.

Table 6 shows the response of the patients to the question'have you observed any type of change in your sexual activity (excitation, erection, ejaculation, or orgasm) since you began taking the drug treatment'. Among those taking risperidone 11 (55\%) responded yes while those taking aripiprazole $3(14.3 \%)$ reported any change in sexual activity. This was statistically significant $(p=0.006)$.

Table 7 shows that majority $92.7 \%$ of the patients did not report about changes in sexual activity spontaneously; only $7.3 \%$ patients reported about sexual changes spontaneously. There was no significant statistical difference $(p=0.065)$ in the two study groups.

Table 8 shows the response of the patients taking the two antipsychotics regarding any decrease in desire for sex was observed or not. Out of those taking risperidone, nine $(45 \%)$, seven (35\%), three (15\%) and one $(5 \%)$ reported no decrease, mild, moderate and severe decrease in desire for sex respectively. Similarly, in the aripiprazole group, $20(95.2 \%)$, one $(4.8 \%)$ reported no change in desire and mild change respectively. There was statistically significant difference in the risperidone and aripiprazole group $(p=0.005)$.

Table 9 shows that seven (35\%), 11 (55\%), two (10\%) patients taking risperidone had no delay, mild delay and moderate delay in ejaculation/orgasm; while among those taking aripiprazole, there was no delay in ejaculation/ orgasm, with statistically significant difference in the two groups $(p=0.000)$.

Table 10 shows the patients in the two study drug groups who were unable to ejaculate or have an orgasm. In the Risperidone group, one (5\%) patient had inability to ejaculate/have an orgasm $25-75 \%$ of the time, 7 (35\%) had it less than $25 \%$ of the time while 12 (60\%) had no difficulty. In the Aripiprazole group 18 (85.7\%) had no difficulty, while three $(14.3 \%)$ had the difficulty less than $25 \%$ of the times. There was no statistically significant difference in the two groups (0.151).

Table 11 shows the frequency of difficulties seen in the patients regarding erection or maintaining it during sexual activity. Those taking risperidone, eight (40\%) had no difficulties, 10 (50\%) had the difficulty sometimes and two (10\%) had it often. In the aripiprazole group, 15 (71.4\%) had no difficulties with obtaining or maintaining erection and six $(28.6 \%)$ had the difficulties with erection sometimes. There was no statistically significant difference in the two 
Table 2. Sex of the Patients.

\begin{tabular}{|c|c|c|c|}
\hline \multirow[t]{2}{*}{ Sex } & \multicolumn{2}{|c|}{ Drug used } & \multirow[t]{2}{*}{ Total } \\
\hline & Risperidone & Aripiprazole & \\
\hline Male & 16 & 17 & 33 \\
\hline Female & 4 & 4 & 8 \\
\hline Total & 20 & 21 & 41 \\
\hline
\end{tabular}

\section{Table 3. Religion of the Patients.}

\begin{tabular}{lccc}
\multicolumn{1}{c}{ Religion } & \multicolumn{2}{c}{ Drug used } & Total \\
& Risperidone & Aripiprazole & \\
\hline Hindu & 17 & 18 & 35 \\
\hline Muslim & 1 & 0 & 18 \\
\hline Christian & 1 & 2 & 3 \\
\hline Buddhist & 1 & 1 & 2 \\
\hline Total & 20 & 20 & 41
\end{tabular}

Table 4. Socioeconomic status

\begin{tabular}{|lccc|}
\hline $\begin{array}{c}\text { Socioeconomic } \\
\text { status }\end{array}$ & \multicolumn{2}{c}{ Drug used } & Total \\
\hline Upper middle & 3 & Aripiprazole & \\
\hline Lower middle & 15 & 4 & 7 \\
\hline Upper lower & 2 & 16 & 31 \\
\hline Total & 20 & 1 & 3 \\
\hline
\end{tabular}

Table 5. Educational status.

\begin{tabular}{|lccc|}
\hline \multicolumn{1}{c}{$\begin{array}{c}\text { Educational } \\
\text { status }\end{array}$} & Risperidone & Aripiprazole & Total \\
\hline $\begin{array}{l}\text { Graduate or } \\
\text { post-graduate }\end{array}$ & 2 & 1 & 3 \\
\hline Intermediate & 4 & 2 & 6 \\
\hline High school & 2 & 6 & 8 \\
\hline Middle school & 3 & 2 & 5 \\
\hline Primary school & 6 & 6 & 12 \\
\hline Illiterate & 3 & 4 & 7 \\
\hline Total & 20 & 21 & 41 \\
\hline
\end{tabular}

Table 6. Response to the inquiry if any type of change in sexual activity was felt after beginning the treatment with risperidone or aripiprazole.

\begin{tabular}{|lccc|}
\hline Drug used & \multicolumn{2}{c}{ Any change in sexual activity } & Total \\
& Risperidone & Aripiprazole & \\
\hline Risperidone & Yes & No & \\
\hline Aripiprazole & $9(45 \%)$ & $11(55 \%)$ & 20 \\
\hline Total & $18(85.7 \%)$ & $3(14.3 \%)$ & 21 \\
\hline
\end{tabular}

drug groups $(p=0.078)$.

Table 12 shows how well did these patients tolerated the changes in sexual functions brought about by the drugs. Those receiving risperidone, eight $(40 \%)$ had no sexual dysfunction, four (20\%) had no problem due to this reason, five $(25 \%)$ had tolerated fairly while three (15\%) reported the dysfunction presenting an important
Table 7. Was the reporting about sexual change spontaneous.

\begin{tabular}{|lccc|} 
Drug used & \multicolumn{2}{c}{$\begin{array}{c}\text { Did the patient spontaneously } \\
\text { report this alteration }\end{array}$} & Total \\
& No & Yes & \\
\hline Risperidone & $17(85 \%)$ & $3(15 \%)$ & 20 \\
\hline Aripiprazole & $21(100 \%)$ & $0(0 \%)$ & 21 \\
\hline Total & $38(92.7 \%)$ & $3(7.3 \%)$ & 41
\end{tabular}

Table 8. Any decrease in desire observed.

\begin{tabular}{|c|c|c|c|c|c|}
\hline \multirow[t]{2}{*}{ Drug used } & \multicolumn{4}{|c|}{ Any decrease in desire for sexual activity } & \multirow[t]{2}{*}{ Total } \\
\hline & $\begin{array}{c}\text { No prob- } \\
\text { lem (0) }\end{array}$ & $\begin{array}{c}\text { Mild } \\
\text { decrease } \\
\text { (1) }\end{array}$ & $\begin{array}{l}\text { Mod- } \\
\text { erate } \\
\text { decrease } \\
(2)\end{array}$ & $\begin{array}{l}\text { Severe } \\
\text { decrease } \\
\text { (3) }\end{array}$ & \\
\hline $\begin{array}{l}\text { Risperi- } \\
\text { done }\end{array}$ & $9(45 \%)$ & $7(35 \%)$ & $3(15 \%)$ & $1(5 \%)$ & 20 \\
\hline $\begin{array}{l}\text { Aripipra- } \\
\text { zole }\end{array}$ & $\begin{array}{l}20 \\
(95.2 \%)\end{array}$ & $1(4.8 \%)$ & $0(0 \%)$ & $0(0 \%)$ & 21 \\
\hline Total & $\begin{array}{l}29 \\
(70.7 \%)\end{array}$ & $8(19.5 \%)$ & $3(7.3 \%)$ & $1(2.4 \%)$ & 41 \\
\hline
\end{tabular}

Table 9. Any delay in ejaculation/orgasm observed.

\begin{tabular}{|c|c|c|c|c|c|}
\hline \multirow{2}{*}{$\begin{array}{l}\text { Drug } \\
\text { used }\end{array}$} & \multicolumn{4}{|c|}{ Was there any delay in ejaculation/orgasm } & \multirow[t]{2}{*}{ Total } \\
\hline & $\begin{array}{l}\text { No delay } \\
\text { (0) }\end{array}$ & $\begin{array}{c}\text { Mild } \\
\text { delay (1) }\end{array}$ & $\begin{array}{l}\text { Moderate } \\
\text { delay (2)) }\end{array}$ & $\begin{array}{l}\text { Intense } \\
\text { delay } \\
\text { (3) }\end{array}$ & \\
\hline $\begin{array}{l}\text { Risperi- } \\
\text { done }\end{array}$ & $7(35 \%)$ & $11(55 \%)$ & $2(10 \%)$ & $0(0 \%)$ & 20 \\
\hline $\begin{array}{l}\text { Aripipra- } \\
\text { zole }\end{array}$ & $21(100 \%)$ & $0(0 \%)$ & $0(0 \%)$ & 0 (0\%) & 21 \\
\hline Total & $\begin{array}{l}28 \\
(68.3 \%)\end{array}$ & $\begin{array}{l}11 \\
(26.8 \%)\end{array}$ & $2(4.9 \%)$ & $0(0 \%)$ & 41 \\
\hline
\end{tabular}

Table 10. Inability to ejaculate or have an orgasm once in sexual relations.

\begin{tabular}{|c|c|c|c|c|c|}
\hline \multirow[t]{2}{*}{ Drug used } & \multicolumn{4}{|c|}{ Inability to ejaculate or have an orgasm } & \multirow[t]{2}{*}{ Total } \\
\hline & $\begin{array}{l}\text { None } \\
(0)\end{array}$ & $\begin{array}{l}\text { Less than } \\
25 \% \text { of } \\
\text { the time } \\
\text { (1) }\end{array}$ & $\begin{array}{l}25-75 \% \text { of } \\
\text { the time } \\
\text { (2) }\end{array}$ & $\begin{array}{l}\text { Always } \\
\text { or almost } \\
\text { always } \\
\text { (3) }\end{array}$ & \\
\hline $\begin{array}{l}\text { Risperi- } \\
\text { done }\end{array}$ & $\begin{array}{l}12 \\
(60 \%)\end{array}$ & $7(35 \%)$ & $1(5 \%)$ & $0(0 \%)$ & 20 \\
\hline $\begin{array}{l}\text { Aripipra- } \\
\text { zole }\end{array}$ & $\begin{array}{l}18 \\
(85.7 \%)\end{array}$ & $3(14.3 \%)$ & $0(0 \%)$ & $0(0 \%)$ & 21 \\
\hline Total & $\begin{array}{l}30 \\
(73.2 \%)\end{array}$ & $10(24.4 \%)$ & $1(2.4 \%)$ & $0(0 \%)$ & 41 \\
\hline
\end{tabular}

Table 11. Any difficulty in obtaining an erection or maintaining once in sexual activity.

\begin{tabular}{|c|c|c|c|c|}
\hline \multirow[t]{2}{*}{ Drug used } & \multicolumn{3}{|c|}{$\begin{array}{c}\text { Any difficulty in obtaining an erection or } \\
\text { maintaining }\end{array}$} & \multirow[t]{2}{*}{ Total } \\
\hline & Never (0) & $\begin{array}{l}\text { Sometimes } \\
\text { (1) }\end{array}$ & Often (2) & \\
\hline $\begin{array}{l}\text { Risperi- } \\
\text { done }\end{array}$ & $8(40 \%)$ & $10(50 \%)$ & $2(10 \%)$ & 20 \\
\hline $\begin{array}{l}\text { Aripipra- } \\
\text { zole }\end{array}$ & 15 (71.4\%) & $6(28.6 \%)$ & $0(0 \%)$ & 21 \\
\hline Total & $23(56.1 \%)$ & 16 (39\%) & 2 (4.9\%) & 41 \\
\hline
\end{tabular}


Table 12. How well have these changes in sexual functions been tolerated.

\begin{tabular}{|c|c|c|c|c|c|}
\hline \multirow[t]{2}{*}{ Drug used } & \multicolumn{4}{|c|}{$\begin{array}{l}\text { How well have you tolerated these changes in } \\
\text { sexual functions }\end{array}$} & \multirow[t]{2}{*}{ Total } \\
\hline & $\begin{array}{l}\text { No sexual } \\
\text { dysfunction } \\
(0)\end{array}$ & $\begin{array}{l}\text { No prob- } \\
\text { lem due to } \\
\text { this reason } \\
\text { (1) }\end{array}$ & Fair (2) & $\begin{array}{l}\text { Poor } \\
\text { (3) }\end{array}$ & \\
\hline $\begin{array}{l}\text { Risperi- } \\
\text { done }\end{array}$ & $8(40 \%)$ & $4(20 \%)$ & $5(25 \%)$ & $3(15 \%)$ & 20 \\
\hline $\begin{array}{l}\text { Aripipra- } \\
\text { zole }\end{array}$ & 13 (61.9\%) & $8(38.1 \%)$ & $0(0 \%)$ & 0 & 21 \\
\hline Total & 21 (51.2\%) & $12(29.3 \%)$ & $\begin{array}{l}5 \\
(12.2 \%)\end{array}$ & $\begin{array}{l}3 \\
(7.3 \%)\end{array}$ & 41 \\
\hline
\end{tabular}

problem. In those receiving aripiprazole, 13 (61.9\%) had no sexual dysfunction, eight (38.1\%) had no problem due to changes brought about by the drug. No patients in the aripiprazole reported the sexual changes bothering them or presenting as an important problem. The difference seen in the patients taking risperidone and aripiprazole was statistically significant $(p=0.015)$.

\section{DISCUSSION}

The responses of the patients to the question- "have you observed any type of change in your sexual activity (excitation, erection, ejaculation, or orgasm) since you began taking the drug treatment' were- among those taking risperidone, $55 \%$ responded yes while those taking aripiprazole $14.3 \%$ reported change in sexual activity. This was statistically significant $(p=0.006)$. Risperidone taking patients reported changes in sexual activity significantly higher than in the aripiprazole taking patients.

Majority, $92.7 \%$ of the patients did not report about changes in sexual activity spontaneously, only $7.3 \%$ patients report about sexual changes spontaneously. There was no significant statistical difference $(p=0.065)$ in the two study groups. Majority did not report about changes in their sexual activity. It could be due to our cultural factors, people having shame on talking about sexual difficulties. Only those who had severe difficulties were likely to report it spontaneously.

Considering response of the patients taking the two antipsychotics regarding any decrease in desire for sex was observed or not- out of those taking risperidone, 9 $(45 \%)$, seven $(35 \%)$, three $(15 \%)$ and one $(5 \%)$ reported no decrease, mild, moderate and severe decrease in desire for sex respectively. Similarly, 20 (95.2\%), one (4.8\%) reported no change in desire and mild change since they began taking aripiprazole respectively. There was statistically significant difference in the risperidone and aripiprazole group ( $p=0.005$ ). Risperidone was seen to cause decrement in desire for sex significantly than aripiprazole.

In the patients taking risperidone, seven (35\%), 11 (55\%), two (10\%) had no delay, mild delay and moderate delay in ejaculation/orgasm while those taking aripiprazole there was no delay in ejaculation/orgasm with statistically significant difference in the two groups $(p=0.000)$.

A higher proportion of men with schizophrenia treated with risperidone had at least one sexual dysfunction, lacked sexual desire and reported problems with sexual arousal and ejaculation. Women with schizophrenia were more likely to report problems with sexual arousal and galactorrhea. ${ }^{7}$ The most frequently reported adverse effect associated with treatment emergent hyperprolactinemia for both men and women was diminished sexual desire (" $40 \%) .^{8}$

In the Risperidone group, one (5\%) patient had inability to ejaculate/have an orgasm $25-75 \%$ of the time, seven (35\%) had it less than $25 \%$ of the time while $12(60 \%)$ had no difficulty. In the Aripiprazole group 18 (85.7\%) had no difficulty while three (14.3\%) had the difficulty less than $25 \%$ of the times. There was no statistically significant difference in the two groups (0.151).

The frequency of difficulties seen in the patients regarding erection or maintaining it during sexual activity- those taking risperidone, eight (40\%) had no difficulties, 10 $(50 \%)$ had the difficulty sometimes and two $(10 \%)$ had it often. In the aripiprazole group, 15 (71.4\%) had no difficulties with obtaining or maintaining erection and six (28.6\%) had the difficulties with erection sometimes. There was no statistically significant difference in the two drug groups $(p=0.078)$. Sexual dysfunction and raised prolactin are common adverse effects of many anti-psychotics. Aripiprazole is an atypical anti-psychotic associated with a reduction in prolactin level in anti-psychotic-induced hyperprolactinaemia. Switching to aripiprazole or the addition of aripiprazole to another antipsychotic regime is associated with a reduction in sexual dysfunction. ${ }^{9}$

In a similar study, risperidone was associated with the most frequent overall sexual impairment (96\%) compared to olanzapine $(90 \%)$ and quetiapine $(88 \%)$, although it was not statistically significant. Melkersson has also reported an overall sexual dysfunction of $89 \%$ due to risperidone. ${ }^{10}$

Considering how well did these patients tolerated the changes in sexual functions brought about by the drugs - those receiving risperidone, eight (40\%) had no sexual dysfunction, four (20\%) had no problem due to this reason, five $(25 \%)$ had tolerated fairly while three (15\%) reported the dysfunction presenting an important problem. In those receiving aripiprazole, 21 (51.2\%) had no sexual dysfunction, eight (38.1\%) had no problem due to changes brought about by the drug. No patients in the aripiprazole reported the sexual changes bothering them or presenting as an important problem. The difference seen in the patients taking risperidone and aripiprazole was statistically significant $(p=0.015)$. In a similar study comparing risperidone and aripiprazole in schizophrenia, sexual dysfunction was significantly higher with risperdone with mean prolactin levels decreasing with aripiprazole but significantly high, five-fold with risperidone. ${ }^{11}$ 


\section{CONCLUSION}

Sexual dysfunction in patients taking risperidone is significant. It should be specifically inquired to assess the difficulties due to the drugs in sex life, otherwise it is not

\section{REFERENCES}

1. Cynthia AG, John B. The sexual dysfunctions. In: Michael GG, Nancy CA, Juan JL, John RG editors. New Oxford textbook of Psychiatry. 2nd edition. New York: Oxford University press; 2009.p. 821-32.

2. Katja K, Christine R, Sandra S, Franziska S, Heike H, Werner K et.al. Wiley library online (homepage on internet). John Wiley \& Sons, Ltd: [updated 2008 May 20; cited 2012 Oct 18]. Available from: http//: www.thecochranelibrary.com/.

3. Daves JM, Chen N, Glick ID. A meta-analysis of the efficacy of secondgeneration antipsychotics. Arch Gen Psychiatry 2003; 60: 553-64.

4. American Psychiatric Association. Diagnostic and statistical manual of mental disorders. 4th ed (DSM-IV-TR). Washington, DC: APA;1994.

5. American psychiatric association. Practice guideline for the treatment of patients with schizophrenia. 2nd ed. Washington dc: merican psychiatric press; 2004.

6. Rettenbacher MA, Hofer A, Ebenbichler C. Prolactin levels and sexual adverse effects in patients with schizophrenia during antipsychotic treatment. J Clin Psychopharmacol 2010; 30:711-15. reported spontaneously unless it is severe. The newer drug aripiprazole is better tolerated on considering the sexual functions. This seems to address the important disabling side effects of risperidone and the first generation antipsychotics.

7. Fortier P, Mottard J-P, Trudel G, Even-Gaudin S. Comparative study of sexuality-related characteristics in young adults with schizophrenia treated with novel neuroleptics and in normal young adults. Acta Psychiatrica Scandiavica 2002;106(413):69-106.

8. Rettenbacher MA, Hofer A, Ebenbichler $\mathrm{Cl}$. Prolactin levels and sexual adverse effects in patients with schizophrenia during antipsychotic treatment. J Clin Psychopharmacol 2010; 30:711-15.

9. Amna M, Kuppuswami SK, Richard JW. Change in sexual dysfunction with aripiprazole: a switching or add-on study. J Psychopharmacol 2008; 22:244-53.

10. Atmaca M, Kuloglu M, Tezcan E. A new atypical antipsychotic: Quetiapine-induced sexual dysfunctions. Int J Impot Res 2005; 17:201-3.

11. Steven G, Saha AR, Mary JK, Carson WH, Ali M, Elyse S et al. Aripiprazole, an Antipsychotic With a Novel Mechanism of Action, and Risperidone vs Placebo in Patients With Schizophrenia and Schizoaffective Disorder. Arch Gen Psychiatry 2003;60(7):681-690. 